\title{
Development of severe psychological distress among low-income individuals during the COVID- 19 pandemic: Iongitudinal study
}

Hiroyuki Kikuchi, Masaki Machida, Itaru Nakamura, Reiko Saito, Yuko Odagiri, Takako Kojima, Hidehiro Watanabe and Shigeru Inoue

\section{Background}

It has been indicated that the health impact of COVID-19 is potentially greater in individuals from lower socioeconomic status than in the overall population.

\section{Aims}

To examine how the spread of COVID-19 has altered the general public's mental health, and whether such changes differ in relation to individual income.

\section{Method}

An online longitudinal survey was conducted at three different time periods during the pandemic. We recruited 1993 people aged 20-70 years, living in the Tokyo metropolitan area in Japan. Participants' mental health was measured with the six-item version of the Kessler Psychological Distress Scale; the existence of severe psychological distress was ascertained through the cut-off data. Multiple logistic and mixed-model ordinal logistic regression analyses were performed, with income as the independent variable.

\section{Results}

Of the participants, 985 were male, with a mean age of 50.5 $( \pm 15.8)$ years. Severe psychological distress percentages for each tested period were $9.3 \%, 11.2 \%$ and $10.7 \%$ for phases 1.2 and 3 , respectively. Between phases 1 and 2 or phases 2 and 3 , the group that earned $<£ 15000$ had significantly higher propensity to develop severe psychological distress than the group that earned $\geq £ 45000$ (odds ratio 2.09 , 95\% Cl 0.95-4.56 between phases 1 and 2; odds ratio 3.00, 95\% $\mathrm{Cl} 1.01-9.58$ between phases 2 and 3 ).

\section{Conclusions}

Although there has been significant deterioration in mental health among citizens during the COVID-19 pandemic, this was more significant among those with lower income. Therefore, mental health measures that focus on low socioeconomic groups may be necessary.

\section{Keywords}

Novel coronavirus; general population; inequality; socioeconomic status; mental health.

\section{Copyright and usage}

(c) The Author(s), 2021. Published by Cambridge University Press on behalf of the Royal College of Psychiatrists. This is an Open Access article, distributed under the terms of the Creative Commons Attribution-NonCommercial-ShareAlike licence (http://creativecommons.org/licenses/by-nc-sa/4.0/), which permits non-commercial re-use, distribution, and reproduction in any medium, provided the same Creative commons licence is included and the original work is properly cited. The written permission of Cambridge University Press must be obtained for commercial re-use.
COVID-19 spread from China to the rest of the world, and was declared a pandemic by the World Health Organization (WHO) in March 2020. As of 15 June 2020, the total number of people who had contracted COVID-19 was 7.5 million, globally, with over 300000 deaths from the disease. ${ }^{1}$ This pandemic negatively affects the mental health of the general public by instilling fear of infection, isolation and death; lowering access to mental healthcare; increasing the sense of isolation through physical distancing; and affecting economic activities (e.g. leading to a decline in wages and/or redundancy). ${ }^{2-4}$ The deterioration in individuals' mental health caused by COVID-19 has been identified as holding a risk for the development of secondary issues, such as increases in alcoholism, domestic violence and suicide., ${ }^{2,5,6}$ On 13 May 2020, the WHO announced its 'Policy Brief: COVID-19 and the Need for Action on Mental Health', which advocated tackling mental health measures parallel to conducting transmission control as part of COVID-19 countermeasures. ${ }^{7}$

\section{General impact of COVID-19}

Some have opined that the health impact of the COVID-19 pandemic has not been uniform across the board; rather, its greatest impact seems to be among those from lower socioeconomic groups. $^{8}$ There are, inherently, 'social determinants of health inequality' that determine individuals' health in the low socioeconomic group, which include poverty, unhygienic environments, unhealthy diet, few educational opportunities and low employment skills. ${ }^{9}$ The recent COVID-19 pandemic has also caused various economic crises that have resulted in decline in wages, redundancy and a general loss of employment across various industries. ${ }^{10}$ It should be noted that during the epidemics of the Spanish Flu (H1N1 influenza A virus) in the 1920s and severe acute respiratory syndrome in 2003 , the number of suicide deaths increased as a result of the economic impact of the infectious disease epidemicity, which led to a deterioration in mental health. ${ }^{11,12}$ Similarly, it can be hypothesised that during the COVID-19 pandemic, the low socioeconomic group, with its increased financial vulnerability, is a high-risk group compared with higher socioeconomic groups. This hypothesis is based on how the former may be more likely to experience worsening of their mental health, which, in turn, could lead to a propensity toward more serious situations, such as suicide.

\section{Impact on mental health}

Considering the health impact on the lower socioeconomic group, it can also be hypothesised that deterioration in mental health would occur compared with higher socioeconomic groups. People with low income would be hesitant to seek medical care because of the related healthcare costs, even when they feel severe anxiety or depression. In addition, their occupations tend to be in restaurants 
or grocery stores, where remote working is not allowed. Furthermore, a report indicates that such workplaces do not provide sufficient personal protective equipment, such as face masks. ${ }^{13}$ Therefore, it can be said that they have no choice but to work in such an environment, to make a living, even if there is fear of COVID-19 infection or death.

Although there have been some cross-sectional studies ${ }^{14}$ that have examined the correlation between socioeconomic factors and mental health during the COVID-19 pandemic, there are almost no longitudinal studies in this regard. Wang et al conducted a study at two time points, with a total of 1738 participants; however, the individuals examined at the two time points were different. ${ }^{15}$ As a result, the study could not discuss how mental health had changed among individuals. To examine whether the impact of the COVID-19 pandemic on mental health is greater among those of low socioeconomic standing compared with those in higher socioeconomic groups, it is necessary to conduct a longitudinal study that follows individuals to capture any changes in their mental health. However, currently, there is insufficient evidence to support this, and there have been indications that further research is needed. ${ }^{6,16}$ To that end, this study employed longitudinal data that followed members of the Japanese general public in the Tokyo metropolitan area, at three different time points. Through such measures, we clarify how the mental health of citizens has changed during the COVID-19 pandemic, and examine whether the degree of such changes differs depending on an individual's socioeconomic status.

\section{Method}

\section{Study sample and data collection}

This was an online longitudinal study conducted with members of the Japanese population. The details of this study are only briefly addressed here, since the subject recruitment method is described in more detail in our previous study. ${ }^{17}$ The 8156 individuals who were approached to be part of this study were those registered with My Voice Co., Ltd., an online survey company. The participants reside in the seven prefectures (Ibaraki, Tochigi, Gunma, Saitama, Chiba, Kanagawa and Tokyo) of the Tokyo metropolitan area. To obtain responses from a total of 2400 people, 200 respondents from each gender/age group (i.e. 20-29, 30-39, 40-49, 50-59, 60-69 and 70-79 years) were selected. First, the study's questionnaire was uploaded onto a secured online platform and the online survey company sent the questionnaire's address page for responses to its registered users. Then, the respondents who received the address could access the online questionnaire, and respond voluntarily. The responses were closed at the point where the set quotient had been met (i.e. 200 respondents per each gender/age group). It should be noted that the survey respondents registered on the site are paid points equivalent to 50 Japanese Yen (approximately 40 pence) for each completed survey.

\section{Survey dates with respect to the spread of COVID-19 in Japan}

This study was conducted at three different time points (phases 1-3) (Fig. 1). The baseline survey (phase 1) was conducted between 25 and 27 February 2020. These dates corresponded with the early phase of the COVID-19 outbreak in Japan. The infection cases in Japan, up to that point, were mainly people returning from outbreak areas (e.g. China) and those who had come into contact with such people. As such, there were not many cases whose route of infection could not be traced. The total number of patients infected with COVID-19 up until 25 February 2020, the day before the survey, was 157 patients in Japan, with 1 death (this death was of a patient who had been infected on a cruise ship from China that had stopped at a Japanese port, and was not a case where COVID-19 was contracted within Japan). ${ }^{1}$

A follow-up study (phase 2) of the respondents who took part in phase 1 was conducted between 1 and 6 April 2020. Between phases 1 and 2, the WHO had pronounced COVID-19 to be a pandemic (11 March 2020). Within Japan, the outbreak had also shifted from the initial phase (i.e. from when a sporadic outbreak was seen) to a community transmission phase (i.e. when the number of patients per day kept increasing exponentially). During this period, the Japanese government started taking infection control measures, such as requesting schools to close temporarily and for companies to work remotely. On 7 April 2020, the final research date, a state of emergency was declared within the Tokyo metropolitan area. ${ }^{18,19}$ The total number of infected patients in Japan at the start of phase 2 was 4477, with a total of 98 deaths.

Phase 3 was conducted between 12 and 17 May 2020. The COVID-19 outbreak in Japan between phases 2 and 3 saw the number of newly infected persons begin to decrease, and the pandemic was believed to have shifted to its 'post-peak' phase. A state of emergency was declared during this period, where Japanese citizens refrained from going outside and companies and schools widely continued to halt their operations. By 11 May 2020, the day before phase 3 research took place, there were 16014 infected patients and 657 deaths.

\section{Measurement}

\section{Assessment of severe psychological distress}

In both the baseline and follow-up surveys, the six-item Kessler Psychological Distress Scale (K6) was used to measure severe psychological distress (SPD) ${ }^{20}$ The K6 is broadly used in epidemiological studies ${ }^{21}$ because it measures psychological distress in the general population by using six simple items. Each item measures the extent of general, non-specific psychological distress, using a five-point response ( 0 'none of the time', 1 'a little of the time', 2 'some of the time', 3 'most of the time', and 4 'all of the time'); thus, the total scores ranged from 0 to 24 . The K6 was translated into Japanese, and a previous study of 164 Japanese adults proved its internal consistency in relation to reliability (Cronbach's alpha, 0.849$)$ and validity (100\% sensitivity and $69.3 \%$ specificity for screening mood and anxiety disorder). ${ }^{22}$ This study used an established protocol to define a score of $\geq 13$ as having SPD. ${ }^{20}$

\section{Assessment of annual income levels}

In this study, individual annual income was set as an independent variable. Annual income was divided into four categories: $<¥ 2$ million (approximately $£ 15000$ ), $¥ 2$ million to $<¥ 4$ million ( $£ 15000$ to $<£ 30000$ ), $¥ 4$ million to $<¥ 6$ million ( $£ 30000$ to $<£ 45000$ ) and $\geq ¥ 6$ million $(\geq £ 45000)$. Information on annual income was provided to the research team in phase 1 , as the research company investigated and ascertained each participating individual's annual income for the 6 months before the start of this research.

\section{Covariates}

In the baseline survey, participants reported their gender, age, residential area (Northern Kanto area [Ibaraki, Tochigi, Gunma Prefectures], Saitama Prefecture, Chiba Prefecture, Kanagawa Prefecture, Tokyo Metropolis Area), working status (working, not working), marital status (single, divorced, separated, married), living arrangements (alone, with others but without children, with children aged $\geq 18$ years, with others and children $<18$ years), smoking status (smokers, ex-smokers, non-smokers), alcohol consumption (never, seldom (one to four times per week), often (five 


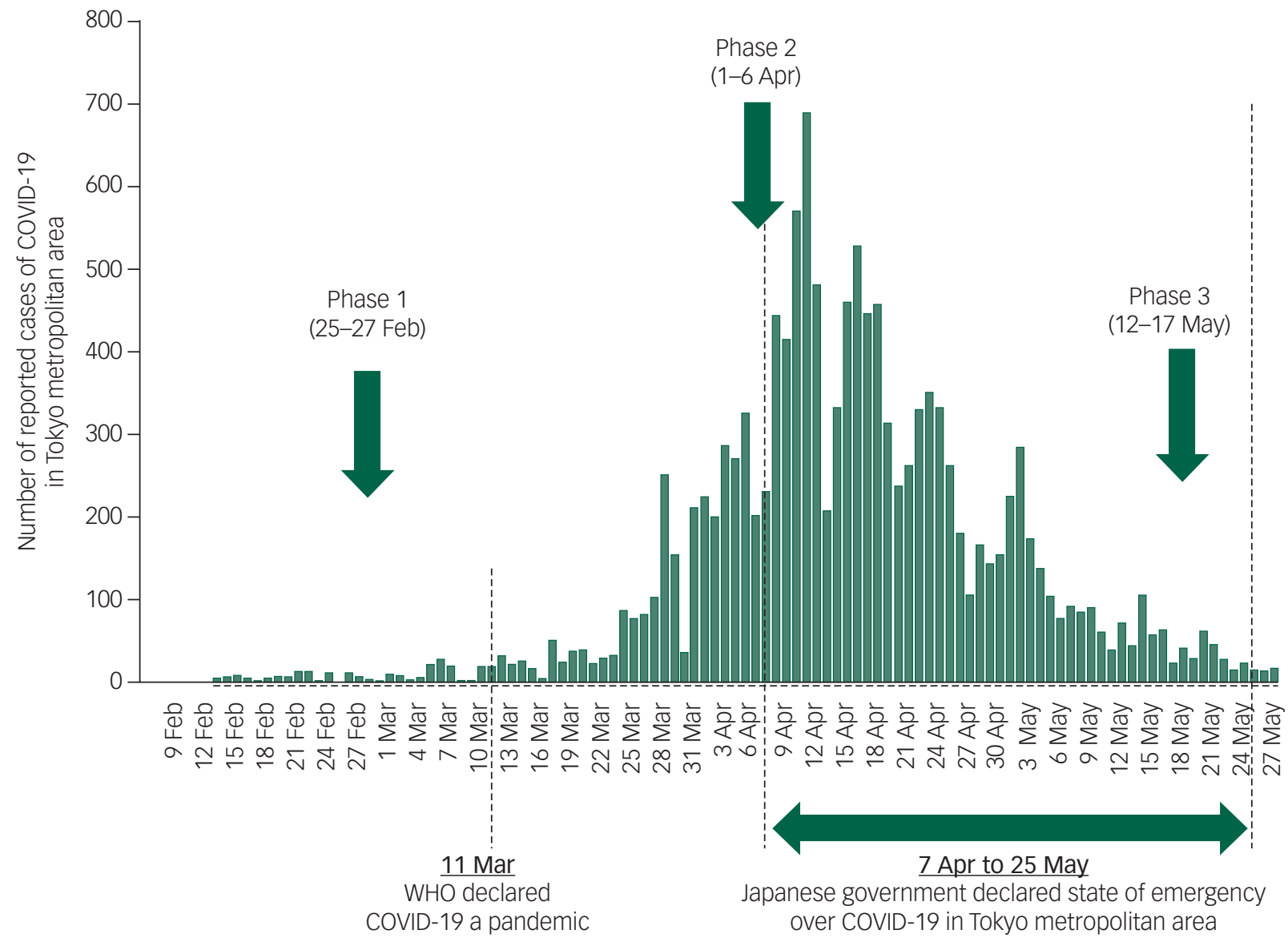

Fig. 1 Timeline of COVID-19 spread in Japan and study time points. WHO, World Health Organization.

to seven times per week), daily walking time ( $<30$ mins, 30-59 mins, 60 mins), regular annual vaccination (yes, no) and past medical history (hypertension, diabetes, heart disease, stroke, respiratory disease, kidney disease, cancer). In addition, the research company provided categorised data of educational attainment (junior or high school graduate, junior college graduate, university graduate or above, other).

\section{Statistical analysis}

SPD percentage was calculated for both the overall and individual factors for each research period (i.e. from phase 1 to phase 3 ), and McNemar's test was conducted to investigate whether there was any significant change in the SPD percentages between the phases. The two-group comparison between the phases was examined with the Bonferroni (multiple comparison) method.

Thereafter, a multiple logistic regression model was used to examine the correlation between annual income and SPD, considering the covariates. First, the relationship between individual annual income and SPD was examined by making use of phase 1 data. Subsequently, a longitudinal analysis was performed, excluding respondents who had SPD in phase 1 . The aim of the analysis was to determine whether new patients had developed SPD between phases 1 and 2. Finally, respondents with SPD at phase 1 or 2 were then excluded, to perform an analysis with SPD onset between phase 2 and phase 3 as the outcome. All covariates were fed into each model simultaneously. Up to four consecutive values were applied to each category of annual income, and the existence of linear tendency was examined in relation to annual income and SPD. An analysis that limited the subject to workers was also conducted as a sensitivity analysis.
Finally, to assess whether SPD status differed by income throughout this survey period, mixed-effects ordinal logistic regression analyses were performed by nesting each participant. ${ }^{23}$ This analysis tested whether the trajectories of SPD proportion in the three surveys differed by income. In this analysis, fixed effects for all individual factors were estimated (model 1), and estimated by further adjusting K6 score at phase 1 to consider the mean difference of the K6 score at phase 1 (model 2). All analyses were performed with Stata for Windows (version 15.0).

\section{Ethical Approval}

This study was approved by the Ethics Committee of Tokyo Medical University, Tokyo, Japan (approval number T2019-0234). Informed consent was obtained from all respondents.

\section{Results}

Table 1 shows the sociodemographic characteristics of the participants and their SPD percentages during the baseline and follow-up surveys. Of the 1993 participants, 985 (49.5\%) were men, the average age was 50.5 (s.d. 15.8) years and approximately $37.2 \%$ were workers.

The SPD percentage of each survey was $9.3 \%$ for phase $1,11.2 \%$ for phase 2 and $10.7 \%$ for phase 3 . McNemar's test indicated a significant deterioration in SPD percentages in participants overall, between phases 1 and 2 . In terms of annual income, the percentages of SPD among those earning $\geq £ 45000$ were $4.2 \%$ (phase 1), $6.9 \%$ (phase 2) and 5.9\% (phase 3), indicating no significant difference in the SPD percentages between phases. Conversely, the percentages 


\begin{tabular}{|c|c|c|c|c|c|c|c|c|c|c|c|}
\hline & \multirow[b]{3}{*}{$n$} & \multirow[b]{3}{*}{$\%$} & \multicolumn{9}{|c|}{ Severe psychological distress $(K 6 \geq 13)$} \\
\hline & & & \multicolumn{2}{|c|}{$\begin{array}{c}\text { Phase } 1 \\
\text { (25-27 Feb) }\end{array}$} & \multicolumn{2}{|c|}{$\begin{array}{l}\text { Phase } 2 \\
\text { (1-7 Apr) }\end{array}$} & \multicolumn{2}{|c|}{$\begin{array}{c}\text { Phase } 3 \\
\text { (12-17 May) }\end{array}$} & \multicolumn{3}{|c|}{ McNemar's test } \\
\hline & & & $n$ & $\%$ & $n$ & $\%$ & $n$ & $\%$ & 1 v. 2 & 1 v. 3 & 2 v. 3 \\
\hline Overall & 1993 & & 186 & $9.33 \%$ & 224 & $11.24 \%$ & 213 & $10.69 \%$ & $0.005^{*}$ & 0.059 & 0.431 \\
\hline \multicolumn{12}{|l|}{ Gender } \\
\hline Male & 985 & $49.47 \%$ & 95 & $9.64 \%$ & 110 & $11.17 \%$ & 103 & $10.46 \%$ & 0.120 & 0.409 & 0.477 \\
\hline Female & 1008 & $50.63 \%$ & 91 & $9.03 \%$ & 114 & $11.31 \%$ & 110 & $10.91 \%$ & $0.016^{*}$ & 0.071 & 0.686 \\
\hline \multicolumn{12}{|l|}{ Age, years } \\
\hline $20-29$ & 268 & $13.46 \%$ & 45 & $16.79 \%$ & 54 & $20.15 \%$ & 41 & $15.30 \%$ & 0.297 & 0.537 & 0.069 \\
\hline $30-39$ & 345 & $17.33 \%$ & 60 & $17.39 \%$ & 57 & $16.52 \%$ & 68 & $19.71 \%$ & 0.895 & 0.276 & 0.101 \\
\hline $40-49$ & 352 & $17.68 \%$ & 35 & $9.94 \%$ & 46 & $13.07 \%$ & 48 & $13.64 \%$ & 0.048 & 0.063 & 0.758 \\
\hline $50-59$ & 342 & $17.18 \%$ & 24 & $7.02 \%$ & 29 & $8.48 \%$ & 28 & $8.19 \%$ & 0.336 & 0.433 & 0.835 \\
\hline $60-69$ & 355 & $17.83 \%$ & 13 & $3.66 \%$ & 23 & $6.48 \%$ & 15 & $4.23 \%$ & 0.499 & 0.655 & 0.088 \\
\hline $70-79$ & 331 & $16.62 \%$ & 9 & $2.72 \%$ & 15 & $4.53 \%$ & 13 & $3.93 \%$ & 0.058 & 0.285 & 0.564 \\
\hline \multicolumn{12}{|l|}{ Annual income, $f$} \\
\hline$<15000$ & 896 & $45.00 \%$ & 101 & $11.27 \%$ & 121 & $13.50 \%$ & 130 & $14.51 \%$ & $0.028^{+}$ & $0.005^{*}$ & 0.361 \\
\hline 15000 to $<30000$ & 504 & $25.31 \%$ & 52 & $10.32 \%$ & 58 & $11.51 \%$ & 46 & $9.13 \%$ & 0.453 & 0.446 & 0.128 \\
\hline 30000 to $<45000$ & 304 & $15.27 \%$ & 21 & $6.91 \%$ & 25 & $8.22 \%$ & 20 & $6.58 \%$ & 0.479 & 0.842 & 0.225 \\
\hline$\geq 45000$ & 289 & $14.52 \%$ & 12 & $4.15 \%$ & 20 & $6.92 \%$ & 17 & $5.88 \%$ & 0.074 & 0.166 & 0.491 \\
\hline \multicolumn{12}{|l|}{ Residential area } \\
\hline Northern Kanto (Ibaraki, Tochigi, Gunma Prefectures) & 177 & $8.89 \%$ & 19 & $10.73 \%$ & 22 & $12.43 \%$ & 19 & $10.73 \%$ & 0.439 & 0.999 & 0.439 \\
\hline Saitama Prefecture & 321 & $16.12 \%$ & 34 & $10.59 \%$ & 41 & $12.77 \%$ & 39 & $12.15 \%$ & 0.317 & 0.423 & 0.732 \\
\hline Chiba Prefecture & 291 & $14.62 \%$ & 24 & $8.25 \%$ & 25 & $8.59 \%$ & 32 & $11.00 \%$ & 0.862 & 0.182 & 0.194 \\
\hline Tokyo Metropolis & 771 & $38.72 \%$ & 67 & $8.69 \%$ & 91 & $11.80 \%$ & 76 & $9.86 \%$ & $0.003^{*}$ & 0.249 & 0.067 \\
\hline Kanagawa Prefecture & 433 & $21.75 \%$ & 42 & $9.70 \%$ & 45 & $10.39 \%$ & 47 & $10.85 \%$ & 0.555 & 0.475 & 0.777 \\
\hline Working status & & & & & & & & & & & \\
\hline No & 741 & $37.22 \%$ & 61 & $8.23 \%$ & 71 & $9.58 \%$ & 80 & $10.80 \%$ & $0.012^{*}$ & $0.015^{*}$ & 0.260 \\
\hline Yes & 1252 & $62.88 \%$ & 125 & $9.98 \%$ & 146 & $11.66 \%$ & 133 & $10.62 \%$ & 0.080 & 0.261 & 0.800 \\
\hline Marital status & & & & & & & & & & & \\
\hline Single, divorced, separated & 834 & $41.89 \%$ & 119 & $14.27 \%$ & 134 & $16.07 \%$ & 131 & $15.71 \%$ & 0.127 & 0.261 & 0.770 \\
\hline Married & 1159 & $58.21 \%$ & 67 & $5.78 \%$ & 90 & $7.77 \%$ & 82 & $7.08 \%$ & $0.015^{*}$ & 0.116 & 0.399 \\
\hline Living arrangement & & & & & & & & & & & \\
\hline Living alone & 384 & $19.29 \%$ & 43 & $11.20 \%$ & 50 & $13.02 \%$ & 46 & $11.98 \%$ & 0.336 & 0.680 & 0.516 \\
\hline Living with others but without children & 945 & $47.46 \%$ & 96 & $10.16 \%$ & 119 & $12.59 \%$ & 120 & $12.70 \%$ & $<0.001^{*}$ & $0.020^{+}$ & 0.923 \\
\hline Living with children aged $\geq 18$ years & 335 & $16.83 \%$ & 12 & $3.58 \%$ & 19 & $5.67 \%$ & 16 & $4.78 \%$ & 0.127 & 0.371 & 0.467 \\
\hline Living with children aged $<18$ years & 329 & $16.52 \%$ & 35 & $10.64 \%$ & 36 & $10.94 \%$ & 31 & $9.42 \%$ & 0.879 & 0.493 & 0.384 \\
\hline Education (years) & & & & & & & & & & & \\
\hline Junior or high school graduate ( $\leq 12$ years) & 468 & $23.51 \%$ & 54 & $11.54 \%$ & 64 & $13.68 \%$ & 56 & $11.97 \%$ & 0.101 & 0.790 & 0.258 \\
\hline Junior college graduate (13-15 years) & 422 & $21.20 \%$ & 32 & $7.58 \%$ & 41 & $9.72 \%$ & 51 & $12.09 \%$ & 0.114 & $0.004^{*}$ & 0.105 \\
\hline University graduate or above ( $\geq 16$ years) & 1078 & $54.14 \%$ & 96 & $8.91 \%$ & 117 & $10.85 \%$ & 103 & $9.55 \%$ & 0.050 & 0.495 & 0.170 \\
\hline Other & 25 & $1.26 \%$ & 4 & $16.00 \%$ & 2 & $8.00 \%$ & 3 & $12.00 \%$ & 0.317 & 0.999 & 0.564 \\
\hline Smoking status & & & & & & & & & & & \\
\hline Smoker & 301 & $15.12 \%$ & 29 & $9.63 \%$ & 36 & $11.96 \%$ & 28 & $9.30 \%$ & 0.206 & 0.862 & 0.144 \\
\hline Ex-smoker & 296 & $14.87 \%$ & 23 & $7.77 \%$ & 28 & $9.46 \%$ & 21 & $7.09 \%$ & 0.273 & 0.683 & 0.162 \\
\hline Non-smoker & 1396 & $70.12 \%$ & 134 & $9.60 \%$ & 160 & $11.46 \%$ & 164 & $11.75 \%$ & $0.025^{+}$ & $0.014^{*}$ & 0.735 \\
\hline Alcohol consumption & & & & & & & & & & & \\
\hline None & 843 & $42.34 \%$ & 98 & $11.63 \%$ & 101 & $11.98 \%$ & 108 & $12.81 \%$ & 0.838 & 0.297 & 0.473 \\
\hline Seldom (1-4 days per week) & 711 & $35.71 \%$ & 59 & $8.30 \%$ & 78 & $10.97 \%$ & 76 & $10.69 \%$ & $0.009^{*}$ & 0.047 & 0.803 \\
\hline Often (5-7 days per week) & 439 & $22.05 \%$ & 29 & $6.61 \%$ & 45 & $10.25 \%$ & 29 & $6.61 \%$ & $0.015^{*}$ & 0.999 & $0.008^{*}$ \\
\hline Walking time (mins per day) & & & & & & & & & & & \\
\hline$<30$ & 1005 & $50.48 \%$ & 112 & $11.14 \%$ & 133 & $13.23 \%$ & 125 & $12.44 \%$ & 0.039 & 0.229 & 0.424 \\
\hline $30-59$ & 659 & $33.10 \%$ & 47 & $7.13 \%$ & 63 & $9.56 \%$ & 58 & $8.80 \%$ & 0.052 & 0.138 & 0.535 \\
\hline$\geq 60$ & 329 & $16.52 \%$ & 27 & $8.21 \%$ & 28 & $8.51 \%$ & 30 & $9.12 \%$ & 0.602 & 0.602 & 0.715 \\
\hline Regular vaccinations & & & & & & & & & & & \\
\hline No & 1115 & $56.00 \%$ & 113 & $10.13 \%$ & 128 & $11.48 \%$ & 131 & $11.75 \%$ & 0.119 & 0.098 & 0.776 \\
\hline Yes & 878 & $44.10 \%$ & 73 & $8.31 \%$ & 96 & $10.93 \%$ & 82 & $9.34 \%$ & $0.014^{*}$ & 0.335 & 0.127 \\
\hline Comorbidities & & & & & & & & & & & \\
\hline Hypertension & 381 & $19.14 \%$ & 24 & $6.30 \%$ & 32 & $8.40 \%$ & 28 & $7.35 \%$ & 0.178 & 0.450 & 0.371 \\
\hline Diabetes & 118 & $5.93 \%$ & 10 & $8.47 \%$ & 12 & $10.17 \%$ & 5 & $4.24 \%$ & 0.480 & 0.096 & $0.020^{+}$ \\
\hline Heart disease & 58 & $2.91 \%$ & 5 & $8.62 \%$ & 9 & $15.52 \%$ & 5 & $8.62 \%$ & 0.059 & 0.999 & 0.046 \\
\hline Stroke & 18 & $0.90 \%$ & 4 & $22.22 \%$ & 4 & $22.22 \%$ & 3 & $16.67 \%$ & 1.000 & 0.317 & 0.317 \\
\hline Respiratory disease & 83 & $4.17 \%$ & 14 & $16.87 \%$ & 19 & $22.89 \%$ & 16 & $19.28 \%$ & 0.157 & 0.564 & 0.366 \\
\hline Kidney disease & 10 & $0.50 \%$ & 1 & $10.00 \%$ & 2 & $20.00 \%$ & 1 & $10.00 \%$ & 0.317 & 0.999 & 0.317 \\
\hline Cancer & 41 & $2.06 \%$ & 2 & $4.88 \%$ & 3 & $7.32 \%$ & 3 & $7.32 \%$ & 0.564 & 0.317 & 0.999 \\
\hline
\end{tabular}


of SPD in the group earning $<£ 15000$ were $11.3 \%$ (phase 1), $13.5 \%$ (phase 2) and $14.5 \%$ (phase 3 ), indicating a significant upward trend between phases 1 and 2, and a significant increase in SPD between phases 1 and 3 .

The results of the logistic regression analysis are shown in Table 2 (also see Supplementary Table 1 available at https://doi. org/10.1192/bjo.2021.5). As an outcome of examining the relationship between SPD prevalence and annual income using phase 1 data, the odds ratio of SPD prevalence in the group with an annual income of $£ 15000$ to $<£ 30000$ compared with the group that reported an annual income of $\geq £ 45000$ was 2.44 (95\% CI $1.19-5.00)$, and the odds ratio in the group with an annual income of $<£ 15000$ was 3.03 (95\% CI 1.44-6.36). Among those without SPD at phase $1(n=1607), 121(7.5 \%)$ had developed SPD at phase 2. Multivariate adjusted logistic regression analysis showed that those with an annual income of $<£ 15000$ were significantly more likely to develop SPD than those with an annual income of $\geq £ 45000$ (odds ratio 2.09, 95\% CI 0.95-4.56). Then, after excluding those with SPD in phase 1 and/or phase $2(n=$ 193), a significantly higher odds ratio was also observed at phase 3 , among the group earning $<£ 15000$ (odds ratio 3.00, 95\% CI 1.01-9.58).

Finally, a mixed-model ordinal logistic regression analysis showing increased likelihood of developing SPD was observed among the lower income group (Fig. 2) (see also Supplementary Fig. 1 and Supplementary Table 2). In model 1, compared with those with higher income ( $\geq £ 45000$ of annual personal income), a significantly high likelihood to develop SPD could be observed among those in the lower ( $£ 15000$ to $£ 30000$ : odds ratio 2.92 , 95\% CI 1.25-6.77) and the lowest income category $(<£ 15000$ : odds ratio 5.56, 95\% CI 2.29-13.46) In model 2, estimated odds ratios were attenuated but the results remained significant in the lowest category (odds ratio 2.30, 95\% CI 1.27-4.18). The results of the sensitivity analysis in which the participants were limited to workers was similar to those for all participants.

In addition, attrition analysis showed no significant differences in the study results, even with the younger participants who dropped out of the study and were lost to follow-up.

\section{Discussion}

\section{Summary of findings}

This study followed 1993 members of the Japanese public in the Tokyo metropolitan area at three different time points (phases $1-3)$, to examine whether there was an onset of SPD caused by the COVID-19 pandemic, depending on annual income level. Results indicated that SPD was more prevalent among those in the lower annual income group than for those in the higher annual income group. Furthermore, lower annual income groups were most likely to experience newly developed SPD (mental health deterioration) even between phases 1 and 2 and phases 1 and 3. These results suggest that the effect of the COVID-19 pandemic on the mental health of citizens shows more deterioration among those with low annual income.

\section{Comparison with past findings}

To the best of our knowledge, there has been only one study that investigated the changes in mental health among general people during the COVID-19 pandemic. Pierce et al used data from 53351 people in the UK and reported that the average score of General Health Questionnaire in 2020 was significantly worse than the score in 2018-2019. ${ }^{24}$ However, contrary to our findings, they found no clear pattern of variation in changes according to

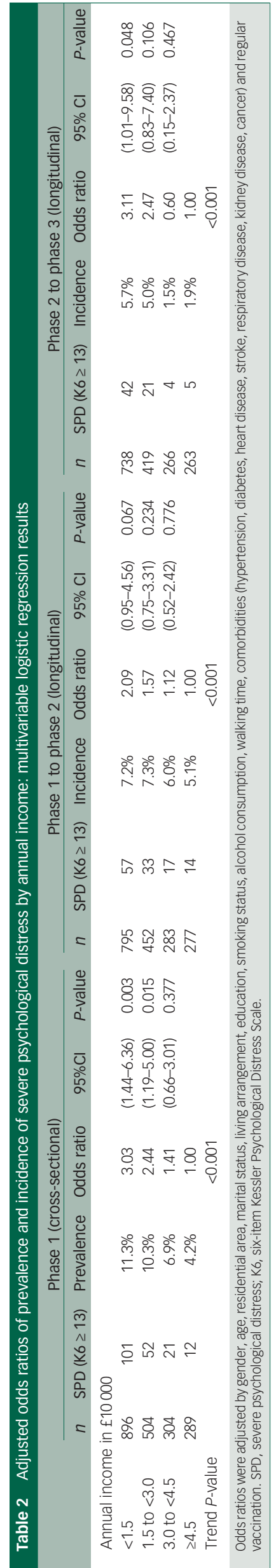




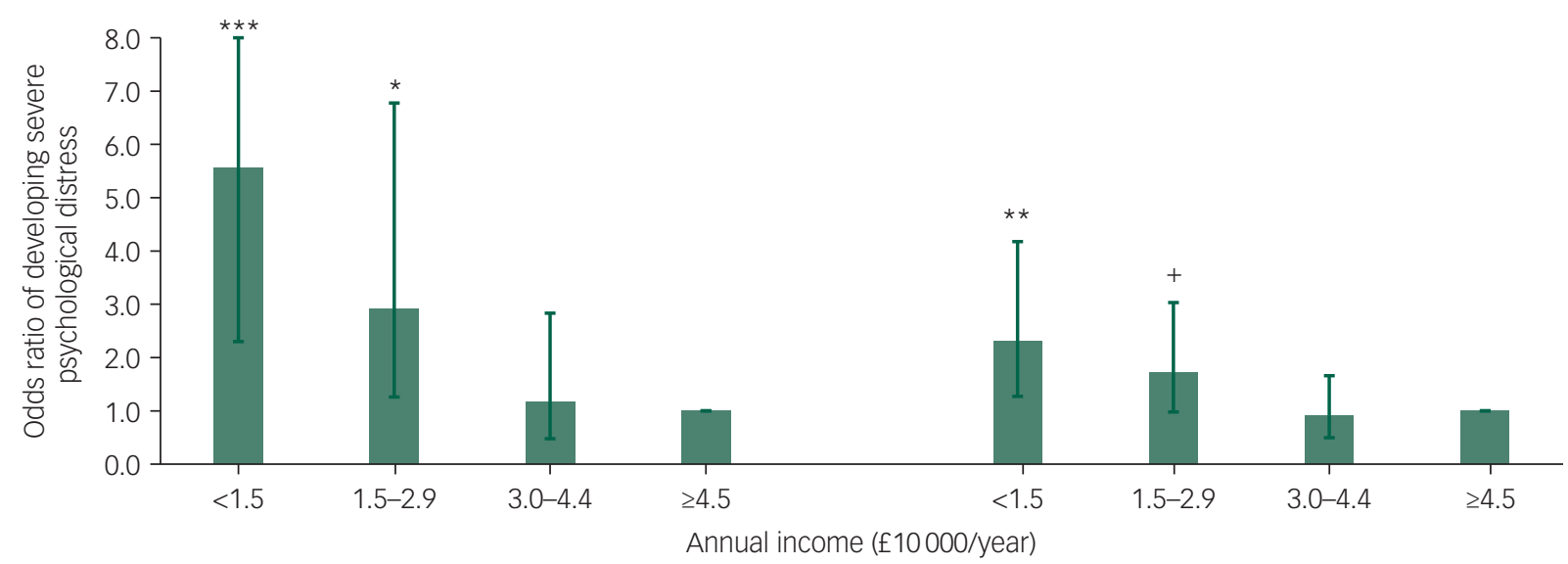

Fig. 2 Adjusted odds ratios of developing severe psychological distress in three phases: mixed-model ordinal logistic regression results. Model 1: odds ratios were adjusted by gender, age, residential area, marital status, living arrangement, education, smoking status, alcohol consumption, walking time, comorbidities (hypertension, diabetes, heart disease, stroke, respiratory disease, kidney disease, cancer) and regular vaccination. Model 2 was further adjusted by total Kessler Psychological Distress Scale score at baseline. ${ }^{* *} P<0.001, * * P<0.01$, $P<0.05,+P<0.1$

income. The impact of the COVID-19 pandemic on the lower income population would be different in each country, which may speculatively be because of the difference in the number of COVID-19 cases or lockdown policies.

Furthermore, this study also showed that those in the young age group (20-40 years) significantly developed SPD compared with older adults (60-70 years; the common retirement age is 65 years in Japan). Considering how previous studies have shown that mental illness is more likely to develop in young people, ${ }^{25}$ younger people with low income may have an excessive risk for developing SPD during the COVID-19 pandemic.

\section{Possible mechanism}

In response to the COVID-19 pandemic, Japan announced the 'Basic Policies for Novel Coronavirus Disease Control by the Government of Japan' on 28 March 2020. ${ }^{19}$ These policies requested that Japanese citizens avoid nonessential outings, reduce social interactions and, if possible, work remotely. These requests were also extended to the operation of services where people gather. From this point onward, various store-based services (e.g. sports gyms, restaurants and concert venues) closed down temporarily in Japan. It should be noted that most of those who work in such service-based facilities tend to be part-time or provisional employees. Because of these closures, their lives may be under increased threat as a result of experiencing a great decline in their income or being made redundant.

In addition, low-income workers tend to be so-called 'essential workers' (e.g. workers in grocery stores, restaurants or factories), where remote work is not possible. It has been reported that Black Americans and Latinos with lower annual income are more likely to be such essential workers in the USA, and that several cases of workplace outbreaks of COVID-19 occurred as a result of inadequate personal protective equipment distribution. ${ }^{13}$ Another study found that the mortality rate of COVID-19 was higher among Black and Latino Americans. ${ }^{26}$ Taken together, it can be speculated that essential workers with low income may be forced to work for a living with excessive fear of being infected with, or dying from COVID-19.

\section{Approach toward the expansion of health inequality for the vulnerable}

Before this pandemic, studies have indicated that income inequality causes depression through mechanisms on the individual level (e.g. feelings of withdrawal or shame), neighbourhood level (e.g. lower social capital) or national level (e.g. lack of investment in housing, education and public transportation, as well as pollution control, healthy food availability and accessibility of healthcare). ${ }^{27}$ The present study also showed a clear association between income level and the proportion of SPD at phase $1(11.27 \%$ and $4.15 \%$ among lowest and highest income category), implying that lower income citizens have suffered from income inequality, affecting their mental health, before this pandemic. In addition, this study showed that the onset of SPD was higher among low-income groups in phases 1-2 and phases 2-3, with both exhibiting linear tendency. Additionally, in phases $2-3$, the group that earned an annual income of $\geq £ 15000$ showed an SPD prevalence decrease of around $1-2 \%$ (from $6.9-11.5 \%$ to $5.9-9.1 \%$ ), whereas the group that earned $<£ 15000$ showed an increase of about $1 \%$ (from $13.5 \%$ to $14.5 \%)$. These findings suggest that the health discrepancy between socioeconomic status may be widening in Japan during the COVID-19 pandemic. In the USA, the mortality rate of Black Americans is higher than for other ethnic groups, in relation to the country's population ratio. ${ }^{26}$ This rate is creating concerns regarding the widening of health discrepancies across the society as a result of the COVID-19 pandemic. ${ }^{28}$ This study showed the gap in the proportion of SPD between lowest and highest income categories, which widened in just 3 months, implying that income inequality may be more severe in Japan. Lower income citizens may feel more withdrawn, lonely or shameful during the COVID19 pandemic, ${ }^{25,29,30}$ which can lead to more unfavourable changes in mental health.

As previously described, the WHO has claimed that mental health measures should take 'a whole of society approach'? Concurrently, perhaps an approach that provides more support to financially vulnerable people is necessary. For example, Japan, at first, proposed providing financial aid of $¥ 300000$ (approximately $£ 2250$ ) strictly to households facing financial difficulties, as an economic measure. However, this approach was criticised by 
Japanese citizens for being unequal. The government, therefore, altered this initial aid, and executed a measure to provide $¥ 100000$ (approximately $£ 750$ ) to all citizens. Based on this study's results, a policy prioritising mental health measures for the financially vulnerable population, in which both resources and time are limited, may be effective from the viewpoint of better equalising health disparities during a pandemic.

\section{Strengths and limitations}

There are some limitations in our study that should be considered. First, since the participants were recruited from among those who had enrolled at a single online research company, the results may have been affected because of selection bias. Relatively little is known about the characteristics of people in online communities. ${ }^{31}$ Second, the study participants were recruited from the Tokyo metropolitan area, but not from all regions of Japan. In addition, the number of participants by age could not be set according to the proportion ratio in Japan. Thus, these results may not be directly applicable to the Japanese population. In addition, compared with middle-aged or older adults, younger adults were more likely to be lost to follow-up, which may cause selection bias. Third, no data on current or past history of medication for mental health were obtained for this study. Differential uptake of mental health interventions (e.g. medication or psychological therapies) could bias the results.

In conclusion, our study found that although the mental health of members of the Japanese public in the Tokyo metropolitan area did deteriorate as a result of the COVID-19 pandemic, the degree of deterioration was noted to be highest among those from lower income levels. Therefore, it may be that mental health countermeasures that focus specifically on low socioeconomic groups are necessary.

Hiroyuki Kikuchi (D), Department of Preventive Medicine and Public Health, Tokyo Medical University, Japan; Masaki Machida, Department of Preventive Medicine and Public Health, Tokyo Medical University, Japan; and Department of Infection Prevention and Control, Tokyo Medical University Hospital, Japan; Itaru Nakamura, Department of Infection Prevention and Control, Tokyo Medical University Hospital, Japan; Reiko Saito Division of International Health (Public Health), Graduate School of Medical and Dental Sciences, Niigata University, Japan; Yuko Odagiri, Department of Preventive Medicine and Public Health, Tokyo Medical University, Japan; Takako Kojima, Department of International Medical Communications, Tokyo Medical University, Japan; Hidehiro Watanabe, Department of Infection Prevention and Control, Tokyo Medical University Hospital, Japan; Shigeru Inoue, Department of Preventive Medicine and Public Health, Tokyo Medical University, Japan

Correspondence: Yuko Odagiri. E-mail: odagiri@tokyo-med.ac.jp

First received 6 Sep 2020, final revision 5 Jan 2021, accepted 8 Jan 2021

\section{Funding}

This work was supported by a grant from Meiji Yasuda Life Foundation of Health and Welfare.

\section{Acknowledgement}

We thank Editage (www.editage.com) for English language editing.

\section{Data availability}

The data-set supporting these findings is not publicly available because of access restrictions imposed by the Tokyo Medical University Ethics Committee. Public data sharing is restricted to protect privacy and confidentiality.

\section{Author contributions}

M.M., I.N. and S.I. conceptualised the study. M.M., H.K. and S.I. were responsible for study methodology and data collection. H.K. conducted the formal analysis. H.K. and S.I. wrote the manuscript. M.M., I.N., R.S., Y.O., T.K. and H.W. reviewed and edited the manuscript.

\section{Supplementary material}

Supplementary material is available online at https://doi.org/10.1192/bjo.2021.5.

\section{Declaration of interest}

None.

\section{References}

1 World Health Organization (WHO). Coronavirus Disease (COVID-2019) Situation Reports. WHO, 2020 (https://www.who.int/emergencies/diseases/novelcoronavirus-2019/situation-reports).

2 Galea S, Merchant RM, Lurie N. The mental health consequences of COVID-19 and physical distancing: the need for prevention and early intervention. JAMA Intern Med 2020;180(6): 817-8.

3 Cowan K. Survey Results: Understanding People's Concerns About the Mental Health Impacts of the COVID-19 Pandemic. MQ: Transforming Mental Health and Academy of Medical Sciences, 2020 (http://www.acmedsci.ac.uk/ COVIDmentalhealthsurveys).

4 Blustein DL, Duffy R, Ferreira JA, Cohen-Scali V, Cinamon RG, Allan BA. Unemployment in the time of COVID-19: a research agenda. J Vocat Behav 2020; 119: 103436

5 Bao Y, Sun Y, Meng S, Shi J, Lu L. 2019-nCoV epidemic: address mental health care to empower society. Lancet 2020; 395: e37-8.

6 Gunnell D, Appleby L, Arensman E, Hawton K, John A, Kapur N, et al. Suicide risk and prevention during the COVID-19 pandemic. Lancet Psychiatry 2020; 7: 468-71.

7 World Health Organization. Policy Brief: COVID-19 and the Need for Action on Mental Health. WHO, 2020 (https://www.un.org/sites/un2.un.org/files/ un_policy_brief-covid_and_mental_health_final.pdf).

8 Dorn AV, Cooney RE, Sabin ML. COVID-19 exacerbating inequalities in the US. Lancet 2020; 395: 1243-4.

9 Marmot M. Social determinants of health inequalities. Lancet 2005; $\mathbf{3 6 5}$ : 1099-104.

10 Nicola M, Alsafi Z, Sohrabi C, Kerwan A, Al-Jabir A, losifidis C, et al. The socioeconomic implications of the coronavirus and COVID-19 pandemic: a review. Int J Surg 2020; 78: 185-93.

11 Yip PSF, Cheung YT, Chau PH, Law YW. The impact of epidemic outbreak: the case of severe acute respiratory syndrome (SARS) and suicide among older adults in Hong Kong. Crisis 2010; 31: 86-92.

12 Wasserman IM. The impact of epidemic, war, prohibition and media on suicide: United States, 1910-1920. Suicide Life-Threatening Behav 1992; 22: 240-54.

13 Lancet T. The plight of essential workers during the COVID-19 pandemic. Lancet 2020; 395: 1587.

14 Rajkumar RP. COVID-19 and mental health: a review of the existing literature. Asian J Psychiatr 2020; 52: 102066.

15 Wang C, Pan R, Wan X, Tan Y, Xu L, McIntyre RS, et al. A longitudinal study on the mental health of general population during the COVID-19 epidemic in China. Brain Behav Immun 2020; 87: 40-8.

16 Hotopf M, Bullmore E, O'Connor RC, Holmes EA. The scope of mental health research in the COVID-19 pandemic and its aftermath. Br J Psychiatry 2020; 217(4): 540-2.

17 Machida M, Nakamura I, Saito R, Nakaya T, Hanibuchi T, Takamiya T, et al. Adoption of personal protective measures by ordinary citizens during the COVID-19 outbreak in Japan. Int J Infect Dis 2020; 94: 139-44.

18 Prime Minister of Japan and His Cabinet. Declaration of a State of Emergency in Response to the Novel Coronavirus Disease (April 7). Cabinet Secretariat, 2020 (https://japan.kantei.go.jp/ongoingtopics/_00018.html).

19 Ministry of Health Labour and Welfare. Basic Policies for Novel Coronavirus Disease Control by the Government of Japan. Ministry of Health Labour and Welfare, 2020 (https://www.mhlw.go.jp/content/10900000/000617686.pdf).

20 Kessler RC, Barker PR, Colpe LJ, Epstein JF, Gfroerer JC, Hiripi E, et al. Screening for serious mental illness in the general population. Arch Gen Psychiatry 2003; 60: $184-9$.

21 Pratt LA. Serious psychological distress, as measured by the K6, and mortality. Ann Epidemiol 2009; 19: 202-9.

22 Furukawa T, Kawakami N, Saitoh M, Ono Y, Nakane Y, Nakamura Y, et al. The performance of the Japanese version of the $\mathrm{K} 6$ and $\mathrm{K} 10$ in the World Mental Health Survey Japan. Int J Methods Psychiatr Res 2008; 17: 152-8.

23 Hedeker D, Gibbons RD. A random-effects ordinal regression model for multilevel analysis. Biometrics 1994; 50: 933-44. 
24 Pierce $\mathrm{M}$, Hope $\mathrm{H}$, Ford $\mathrm{T}$, Hatch $\mathrm{S}$, Hotopf $\mathrm{M}$, John A, et al. Mental health before and during the COVID-19 pandemic: a longitudinal probability sample survey of the UK population. Lancet Psychiatry 2020; 7: 883-92.

25 Palgi Y, Shrira A, Ring L, Bodner E, Avidor S, Bergman Y, et al. The loneliness pandemic: Ioneliness and other concomitants of depression, anxiety and their comorbidity during the COVID-19 outbreak. J Affect Disord 2020; 275: 109-11.

26 Yancy CW. COVID-19 and African Americans. JAMA 2020; 323: 1891.

27 Patel V, Burns JK, Dhingra M, Tarver L, Kohrt BA, Lund C. Income inequality and depression: a systematic review and meta-analysis of the association and a scoping review of mechanisms. World Psychiatry 2018; 17: 76-89.

28 Krouse HJ. COVID-19 and the widening gap in health inequity. Otolaryngol Neck Surg 2020; 163(1): 65-6.

29 Grossman ES, Hoffman YSG, Palgi Y, Shrira A. COVID-19 related loneliness and sleep problems in older adults: worries and resilience as potential moderators. Pers Individ Dif 2021; 168: 110371.

30 Shrira A, Hoffman Y, Bodner E, Palgi Y. COVID-19-related loneliness and psychiatric symptoms among older adults: the buffering role of subjective age. Am J Geriatr Psychiatry 2020; 28(11): 1200-4.

31 Wright KB. Researching internet-based populations: advantages and disadvantages of online survey research, online questionnaire authoring software packages, and web survey services. J Comput Commun 2006; 10: JCMC1034. 